\title{
Heart Rate Variability and Obesity Indices: Emphasis on the Response to Noise and Standing
}

\author{
Jeong A Kim, MD, PhD, Yong-Gyu Park, PhD, Kyung-Hwan Cho, MD, PhD, \\ Myung-Ho Hong, MD, PhD, Hee-Chul Han, MD, PhD, Youn-Seon Choi, MD, PhD, \\ and Dokyung Yoon, $\mathrm{MD}, \mathrm{PhD}$
}

Background: Obese people have a higher prevalence of cardiovascular disease, but the mechanism of this result remains obscure. The purpose of this study was to prove heart rate variability (HRV) response at rest and during stimuli in these persons.

Methods: The subjects were 41 healthy persons (19 men, 22 women) ranging in age from 20 to 65 years. HRV was measured at rest and at given stresses with noise and standing.

Results: Higher levels of fat mass, percentage fat content, and waist/hip ratio were significantly associated with lower low frequency (LF) $(r=-0.34, r=-0.43 ; P<.01, r=-0.33, P<.05)$, and lower root mean square differences of successive NN intervals (RMS standard deviation) $(r=-0.33, r=$ $-0.35, r=-0.38, P<.05)$. During rest, noise, and standing, the change amount of the standard deviation of NN interval (SDNN) and low frequency/high frequency ratio were not different between normal and obese groups $(P>.05)$.

Conclusion: Although there was no significant HRV response to stimuli, root mean square of successive differences (which reflects parasympathetic acivity) and low frequency (which mainly reflects sympathetic activity) were negatively correlated with fat mass, fat percentage, and waist-to-hip ratio at rest in obese persons. These results mean obesity can change cardiac autonomic nervous response, meaning that the mechanism by which obesity increases cardiac mortality would be explained, at least partially. (J Am Board Fam Pract 2005;18:97-103.)

In Korea, as in Western countries, disease related to obesity has increased recently. However, body mass index (BMI) of patients who have obesityrelated diseases is much lower in Korea compared with similar patients in Western countries. For example, average $\mathrm{BMI}$ in patients with non-insulindependent diabetes mellitus is $24.2 \pm 3.4 \mathrm{~kg} / \mathrm{m}^{2}$. The percentage of overweight patients with insulin-dependent diabetes mellitus whose BMI is higher than $25 \mathrm{~kg} / \mathrm{m}^{2}$ is $36 \% .^{1,2}$ This is very low compared with the US level of $60 \%$ to $69 \%$. In addition, some studies showed that the number of insulin-resistant patients with a BMI above 23 $\mathrm{kg} / \mathrm{m}^{2}$ sharply increased. ${ }^{3,4}$ This is because of the

Submitted, revised, 15 October 2004.

From the Department of Family Medicine, Guro Hospital (JAK, M-HH, Y-SC), Department of Family Medicine, Anam Hospital (K-HC), Department of Physiology, College of Medicine and Neuroscience Research Institute (H-CH), and Department of Family Medicine, Ansan Hospital (DY), Korea University, Seoul, South Korea, and the Department of Biostatistics, The Catholic University of Korea, Songeui Campus (Y-GP). Address correspondence to Yong-Gyu Park, PhD, Department of Biostatistics, The Catholic University of Korea, Songeui Campus (e-mail: jakim89@ freechal.com). higher susceptibility of Koreans to diseases related to sugar and fat because of their smaller bodies compared with persons from Western countries. $2,5,6$ Therefore, in Korea, a BMI of $25 \mathrm{~kg} / \mathrm{m}^{2}$ is considered the cutoff value for obesity and 23 $\mathrm{kg} / \mathrm{m}^{2}$ is considered the cutoff value for overweight. ${ }^{7,8}$ These criteria are compatible with World Health Organization Asian9 and Japanese $\mathrm{e}^{10,11}$ obesity criteria.

Despite the relatively consistent findings of increased prevalence of cardiovascular disease in obesity, the reason for these associations remains obscure. Many factors have been suggested as causes for this relationship, such as insulin resistance, hypertension, and reduced high-density lipoprotein. On the other hand, it has also been suggested that a reduction in autonomic function might be the mechanism for the increased prevalence of cardiovascular disease in obesity. ${ }^{12-18}$ However, these studies have not concentrated on the autonomic activity of the heart itself. Heart rate variability (HRV) measures the effect of autonomic function on the heart alone. Therefore, it could be the most useful method by which to investigate the effect of 
obesity on cardiovascular disease. It is important to emphasize the effect of obesity on HRV; decreased HRV significantly increases cardiovascular mortality. ${ }^{19-23}$ Because obesity is related to increased morbidity and mortality in cardiovascular diseases. ${ }^{24-26}$

HRV represents continuous fluctuations in heart rate. R-to-R interval variations on electrocardiograms represent beat-to-beat control mechanisms. Efferent sympathetic and parasympathetic activities directed to the sinus node characterized by each cardiac cycle can be modulated by central and peripheral stimulators. These stimulations generate rhythmic fluctuations in efferent neural discharge that manifest as oscillations in the heart beat period. $^{27,28}$

HRV can be measured by 2 methods: the time domain method and the frequency domain method. In the time domain method, the standard deviation of $\mathrm{NN}$ interval (SDNN) and the root mean square of successive differences in NN intervals (RMSSD) are obtained. SDNN reflects all the cyclic components responsible for variability in the periods of recording, and RMSSD mainly reflects parasympathetic nervous activity. Proper mathematical algorithms can be used to obtain the frequency. In the frequency domain method, the high frequency (HF; 0.15 to $0.40 \mathrm{~Hz}$ ) component is associated solely with parasympathetic activity. ${ }^{29-31}$ The low frequency (LF; 0.04 to $0.15 \mathrm{~Hz}$ ) component is associated with both sympathetic and parasympathetic activity, but sympathetic activity is the greater contributor. ${ }^{30,32-34}$

This study was performed on the assumption that obese persons have a different HRV response at rest and to given stimuli. If obesity can change the HRV response to stimuli as well as the rest state, meaning that obesity can change cardiac autonomic nervous response, so the mechanism by which obesity increases cardiac mortality would be explained, at least partially. To investigate this hypothesis, HRV was measured at rest and in response to such stimuli as noise and standing.

\section{Methods}

\section{Study Subjects}

The subjects were 41 healthy persons ( 19 men and 22 women) ranging in age from 20 to 65 years. They had had a general health check up less than 12 months before the test. All had normal fasting blood glucose $(<126 \mathrm{mg} / \mathrm{dL})$ and were normotensive $(<140 / 90 \mathrm{~mm} \mathrm{Hg})$. None of the subjects was taking medication that might affect the autonomic nervous system. Results of liver, renal, and endocrine function tests were all normal.

An institutional review committee approved the experimental protocols of this study, and all subjects gave informed written consent for participation. Participants in the study abstained from tobacco, caffeinated beverages, and alcohol on the morning of the test day. The tests were performed between 11:30 AM and 1:30 PM and at least 3 hours after a meal.

\section{Experiments}

Obesity Index Measure

The height $(\mathrm{cm})$ and weight $(\mathrm{kg})$ of each participant were measured at the beginning of the study. BMI was calculated as the weight in kilograms divided by the square of the height in meters. The ratio of waist circumference to hip circumference was measured to estimate the centrality of body fat. Body composition such as fat mass and percentage fat content was measured by bioelectric impedance analysis. Impedance analysis was performed with InBody 3.0 (Biospace, Seoul, Korea).

\section{HRV Measures at Rest, during Noise, and during Standing}

After 5 minutes of rest in the supine position, HRV was measured for 5 minutes in the same position. For noise challenge, an audio frequency generator was used. The volume of sound for the 5 minutes' exposure was set at $100 \mathrm{~dB}$ and the frequency at 2 $\mathrm{KHz}$. During the noise exposure, HRV was measured in the supine position for 5 minutes. Finally, HRV was measured in the standing position for 5 minutes.

\section{Equipment for Measuring HRV}

The analysis of HRV was performed with the use of a device (SA-2000; Medicore, Seoul, Korea) that satisfies the standards of the European Society of Cardiology and the North American Society of Pacing and Electrophysiology.

\section{Statistical Methods}

SAS (ver. 6.12; SAS Institute, Cary, NC) was used for all statistical analyses. Each variable was checked for normality of distribution using the Shapiro-Wilk test. Of the HRV measures, SDNN, 
Table 1. Characteristics of Participants $(N=41)$

\begin{tabular}{lc}
\hline & $\begin{array}{c}\text { Mean } \pm \text { SD (\%) } \\
\text { (median, range) }\end{array}$ \\
\hline $\begin{array}{l}\text { Age (year) } \\
\text { Male }\end{array}$ & $45.1 \pm 10.2(44,25-65)$ \\
Heart rate & $19(46.3 \%)$ \\
Obesity index measures & $65.0 \pm 8.9(64.1,50.9-89.6)$ \\
$\quad$ Fat mass $(\mathrm{kg})$ & $17.0 \pm 6.0(16.5,7.1-35.2)$ \\
Fat content $(\%)$ & $26.3 \pm 7.8(26.3,11.2-40.5)$ \\
Waist/Hip & $0.89 \pm 0.05(0.88,0.75-1.0)$ \\
BMI* $\left(\mathrm{kg} / \mathrm{m}^{2}\right)$ & $24.3 \pm 3.3(24.0,17.5-33.4)$ \\
\hline
\end{tabular}

* BMI, body mass index.

RMSSD, LF, and HF, which had significantly rightward-skewed distributions, were log-transformed to produce normalized distributions.

Values were presented as mean, standard deviation, median, and range for demographic variables and mean when analysis of covariance (ANCOVA) was used. Two-sample $t$ tests, Wilcoxon rank sum test, and Pearson and Spearman correlation were used to determine whether the demographic and clinical variables were associated with HRV measures. To detect the differences of HRV measures among the 3 states, the repeated measures by ANCOVA and Bonferroni multiple comparison method were used to guard against an increase in type I error level.

The subjects were divided into 2 groups, separated at the median splits by percentage fat content. Repeated measures by ANCOVA models with one repeated factor (stimuli challenges) and gender, age, and heart rate as covariants were used to determine the effects of those factors.

\section{Results}

\section{Obesity Indices of the Participants}

Basic values and subjects' obesity indices are presented in Table 1. The mean fat mass was $17.0 \pm$
$6.0 \mathrm{~kg}$, mean percentage fat was $26.3 \pm 7.8 \%$, mean waist/hip ratio was $0.89 \pm 0.05$, and mean BMI was $24.3 \pm 3.3 \mathrm{~kg} / \mathrm{m}^{2}$.

\section{Participant's Characteristics and HRV at Rest}

The association between baseline HRV and participants characteristics is presented in Table 2.

Age

SDNN and RMSSD were decreased with increasing age $(r=-0.42, r=-0.53 ; P<.01)$. LF and $\mathrm{HF}$ were also negatively related with increasing age $(r=-0.54, r=-0.46 ; P<.01)$. However, the $\mathrm{LF} / \mathrm{HF}$ ratio did not change $(r=-0.09, P>.05)$.

Sex

LF was significantly higher in men $(P<.05)$. Other variables, such as SDNN, RMSSD, and HF, were higher in men, although not significantly $(P>.05)$.

\section{Heart Rate}

SDNN, RMSSD, LF, and HF were decreased with increasing heart rate $(r=-0.44, r=-0.62, r=$ $-0.39, r=-0.53 ; P<.01)$. On the contrary, $\mathrm{LF} / \mathrm{HF}$ ratio was positively related to heart rate $(r=0.31 ; P<.01)$.

\section{Obesity Indices and HRV at Rest}

The association between obesity and HRV is also presented in Table 3. There was no correlation between HRV and BMI $(P>.05)$. By contrast, a higher level of fat mass, percentage fat, and waist/ hip ratio were significantly associated with lower LF $(r=-0.34, r=-0.43, P<.01 ; r=-0.33, P<$ $.05)$ and lower RMSSD $(r=-0.33, r=-0.35, r=$ $-0.38, P<.05)$.

Table 2. Participant's Characteristics and Heart Rate Variability at Rest $(\mathrm{N}=41)$

\begin{tabular}{lccccc}
\hline & SDNN & RMSSD & LF & HF & LF/HF \\
\hline Age & $-0.42^{\dagger}$ & $-0.53^{\dagger}$ & $-0.54^{\dagger}$ & $-0.46^{\dagger}$ & -0.09 \\
Sex & & & & & \\
$\quad$ Male & $3.73( \pm 0.43)$ & $3.40( \pm 0.65)$ & $5.78( \pm 1.00)$ & $5.20( \pm 1.27)$ & $0.58( \pm 0.82)$ \\
Female & $3.57( \pm 0.42)$ & $3.16( \pm 0.60)$ & $4.95( \pm 1.21)^{*}$ & $4.94( \pm 1.37)$ & $0.00( \pm 1.12)$ \\
Heart rate & $-0.44^{\dagger}$ & $-0.62^{\dagger}$ & $-0.39^{\dagger}$ & $-0.53^{\dagger}$ & $0.31^{*}$ \\
\hline
\end{tabular}

Values are mean $( \pm \mathrm{SD})$ tested by Wilcoxon rank sum test, two-sample $t$ test

${ }^{*} P<.05$.

${ }^{+} P<.01$. 
Table 3. Obesity Indices and Heart Rate Variability at $\operatorname{Rest}(\mathrm{N}=41)$

\begin{tabular}{llllll}
\hline & SDNN $^{\ddagger}$ & RMSSD & LF & HF & LF/HF \\
\hline Fat mass & -0.28 & $-0.33^{*}$ & $-0.34^{*}$ & -0.27 & -0.08 \\
Fat content (\%) & $-0.32^{*}$ & $-0.35^{*}$ & $-0.43 \dagger$ & -0.28 & -0.19 \\
Waist/Hip & -0.30 & $-0.38^{*}$ & $-0.33^{*}$ & -0.30 & -0.05 \\
BMI & -0.11 & -0.20 & -0.15 & -0.10 & -0.10 \\
\hline
\end{tabular}

${ }^{*} P<.05$

${ }^{\dagger} P<.01$

${ }^{\ddagger} \mathrm{SDNN}$, standard deviation of NN interval; RMSSD, root mean square of successive differences of NN intervals; LF, Low Frequency; HF, High Frequency; BMI, body mass index.

\section{HRV Changes during Standing and Noise According to Percentage Fat (after Adjusting for Age, Gender, and Heart Rate)}

Changes of HRV response to stimuli, according to obesity, are shown in Figure 1. All results were adjusted according to age, gender, and heart rate. The median percentage fat content, $26.3 \%$, was used as the cutoff point for the normal $(51.2 \%)$ and obese (48.8\%) groups, respectively.

The change in SDNN was not different $(P>$ $.05)$ between normal and obese group at rest and during noise and standing after adjusting for age, gender, and heart rate (normal group: male, $1.6 \pm$ $0.2,1.7 \pm 0.1,1.3 \pm 0.2$; female, $1.8 \pm 0.2,1.8 \pm$ $0.2,1.5 \pm 0.2$; obese group: male, $1.4 \pm 0.0,1.4 \pm$ $0.0,1.2 \pm 0.0$; female, $1.5 \pm 0.2,1.5 \pm 0.2,1.2 \pm$ $0.2 ; P>.05)$.

In addition, the change amount of LF/HF ratio was not different (normal group: male; $1.5 \pm 0.6$, $0.1 \pm 0.4,0.6 \pm 0.4$, female; $0.6 \pm 0.0,-0.2 \pm 0.3$, $0.0 \pm 0.4$, fatty group: male; $0.7 \pm 0.0,0.4 \pm 0.0$ $1.2 \pm 0.0$, female; $1.2 \pm 0.6,0.0 \pm 0.5,0.3 \pm 0.5$; $P>.05)$.

\section{Discussion}

Significant correlations were observed between HRV and obesity indices at rest. During the resting state, higher levels of fat mass, percentage fat content, and waist/hip ratio were significantly associated with the lower LF variable, which mainly reflects sympathetic activity. The sympathoadrenal system is widely assumed to play a major role in the pathophysiology of obesity because of the regulation of energy expenditure. ${ }^{35}$ RMSSD, which reflects parasympathetic activity, was also negatively related to obesity indices in our study. This result suggests that an obese person might have an auto- nomic function disturbance in parasympathetic activity as well as in sympathetic activity. Among the investigators who have studied the relationship between obesity and autonomic function, there have been marked differences in opinion as to how to interpret the results. ${ }^{12-18}$ One of the main views is that obese people have a higher sympathetic tone, which is proved from elevated catecholamine levels. Another is that obese people have lower sympathetic tone, which is proved from lower LF. In our opinion, these differences of interpretation may arise from confusion concerning the meaning of HRV and sympathetic hormones. HRV is one of the efferent limbs of the autonomic nervous system, not the whole autonomic nervous system function, whereas sympathetic hormone is one of the afferent limbs of the autonomic nervous system. Because of these differences, a higher sympathetic hormone level, as indicated by catecholamine, and a lower sympathetic response activity, as indicated by LF, can be simultaneously observed in an obese person.

Our results showed that obese persons have different HRV at rest but not during stimuli. This means that higher cardiovascular disease in obese person is caused mainly by their different HRV responses at rest state, but not to stimuli. However these results also may be from the intensity or type of stimuli. Therefore, further study is needed in the future.

Many factors that affect HRV have been considered controls. HRV is a valuable tool for risk stratification in cardiovascular disease, but the physiologic effects of many other factors must also be taken into account.

Age was considered. There was a significant correlation between HRV variables and age in our study. All the cyclic components responsible for variability, which were presented by SDNN, decreased with increasing age. LF and HF, which mainly reflect sympathetic and parasympathetic activity, respectively, also decreased with increasing age. This result suggests that both parasympathetic and sympathetic activity decrease with increasing age.

Sex was also considered in our study. Men had a significantly higher LF than women. Therefore, it can be conjectured that men have greater sympathetic activity than women. This higher sympathetic activity could explain why cardiovascular 

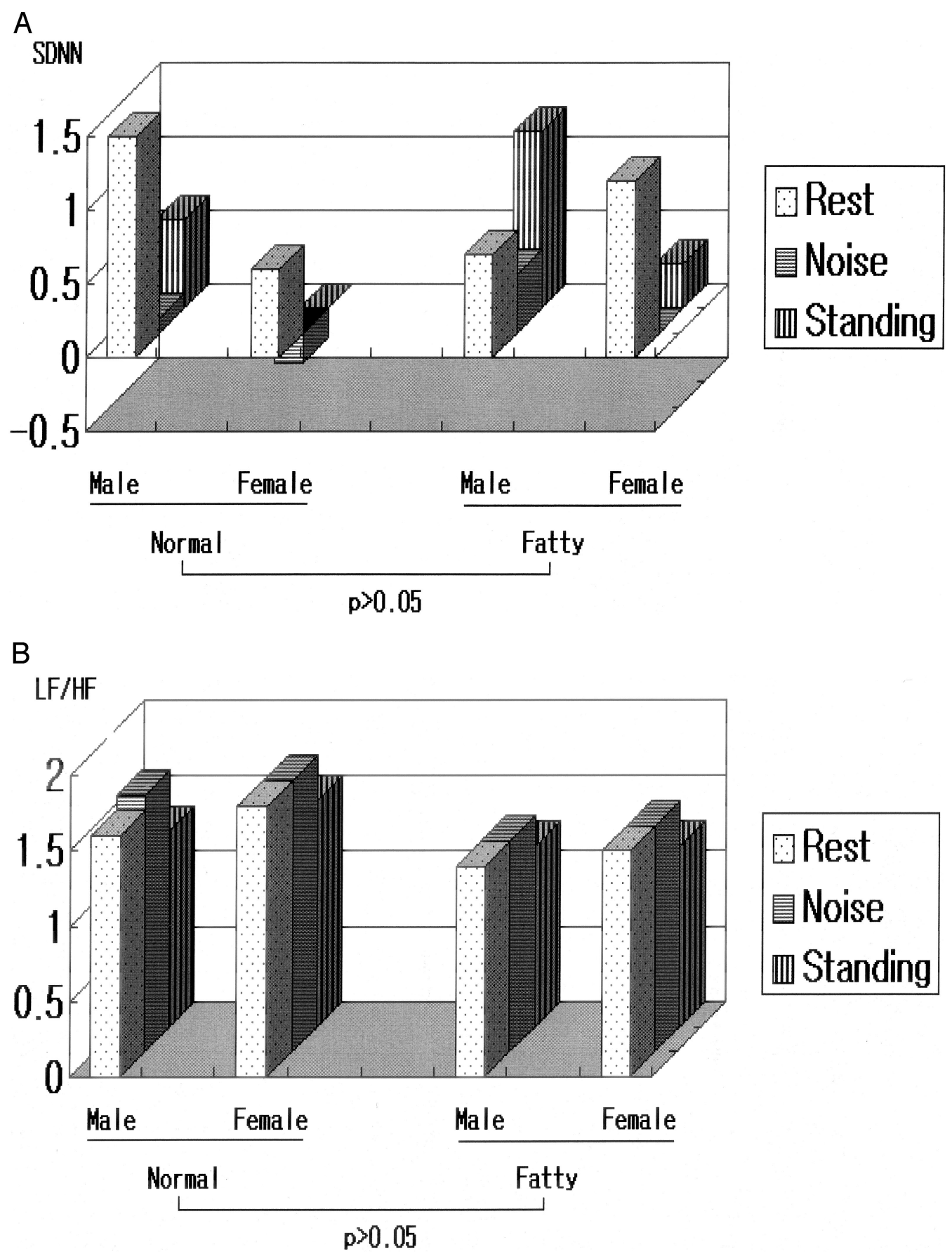

Figure 1. HRV changes in standing and noise according to percent fat (after adjusting for age, gender, and heart rate).

disease is more prevalent in men than women. However, the mean age difference between genders (male, 43 years; female, 46 years) could also explain this result.

Heart rate was also considered. SDNN, RMSSD, LF, and HF were negatively related with increasing heart rate. On the contrary, LF/HF ra- tio was positively related with heart rate $(r=0.31$ $P<.01)$. This is reasonable because increased heart rate is related elevated sympathetic activity.

Although number of subjects in our investigation was small, this is an important study because it dealt with the HRV response to stimuli in obese persons. 


\section{Conclusion}

Although there was no significant HRV response to stimuli in obese persons, RMSSD (which reflect heart rate variability) and LF (which mainly reflects sympathetic activity) were negatively correlated with fat mass, percentage fat content, and waist/hip ratio at rest in obese persons. These results mean obesity can change cardiac autonomic nervous response, meaning that the mechanism by which obesity increases cardiac mortality would be explained, at least partially.

\section{References}

1. Min HK. Non-insulin-dependent diabetes mellitus (NIDDM) in Korea. Diabet Med 1996;13:S13-5.

2. Park JY, Kim HK, Kim MS, Cho BY, Lee HG, Go CS, et al. Body weight changes of non insulin dependent diabetes mellitus in Korea. Korean Journal of Diabetes Association 1993;17:51-8.

3. Chang SA, Kim HS, Yoon KH, et al. Body mass index is the most important determining factor for the degree of insulin resistance in non-obese type 2 diabetic patients in Korea. Metabolism 2004;53: $142-6$.

4. Sung EJ, Sunwoo S, Kim SW, Kim YS. Obesity as a risk factor for non-insulin-dependent diabetes mellitus in Korea. J Korean Med Sci 2001;16:391-6.

5. Min HK. The characteristics of Korean diabetes. Korean J Diabet Assoc 1992;16:163-73.

6. Min HK, Yoo HJ, Lee HK, Kim EJ. Changing patterns of the prevalence of diabetes mellitus in Korea. Korean J Diabet Assoc 1981;6:71.

7. Kim SM, Kim KM, Choi HJ, Yoon SJ, Lee DJ. A Study on the Obesity Index of Health Examination Center Data. J Korean Soc Study Obesity 1997;6: 137-42.

8. Kim SM, Lee DJ, Kim YS, Lee TH. Assessment of anthropometric indices of obesity in Korea. J Korean Soc Study Obesity 2000;9:267-77.

9. Steering Committee. The Asia-Pacific perspective: redefining obesity and its treatment [monograph on the Internet]. Australia: International Diabetes Institute, WHO; 1999 [cited 2004 Oct 15]. Available from: http://www.idi.org.au/downloads/obesity_report.pdf

10. Examination Committee of Criteria for 'Obesity Disease' in Japan; Japan Society for the Study of Obesity. New criteria for 'obesity disease' in Japan. Circ J 2002;66:987-92.

11. Kanazawa M, Yoshiike N, Osaka T, Numba Y, Zimmet $\mathrm{P}$, Inoue $\mathrm{S}$. Criteria and classification of obesity in Japan and Asia-Oceania. Asia Pac J Clin Nutr 2002;11 Suppl 8:S732-7.

12. Laederach-Hofmann K, Mussgay L, Ruddel H. Autonomic cardiovascular regulation in obesity. J Endocrinol 2000;164:59-66.
13. Matsumoto T, Miyawaki C, Ue H, Kanda T, Yoshitake $\mathrm{Y}$, Moritani T. Comparison of thermogenic sympathetic response to food intake between obese and non-obese young women. Obes Res 2001;9: $78-85$.

14. Matsumoto T, Miyawaki T, Ue H, Kanda T, Zenji C, Moritani T. Autonomic responsiveness to acute cold exposure in obese and non-obese young women. Int J Obes Relat Metab Disord 1999;23:793-800.

15. Muscelli E, Emdin M, Natali A, et al. Autonomic and hemodynamic responses to insulin in lean and obese humans. J Clin Endocrinol Metab 1998;83: 2084-90.

16. Oparil S, Oberman A. Nontraditional cardiovascular risk factors. Am J Med Sci 1999;317:193-207.

17. Spraul M, Ravussin E, Fontvieille AM, Rising R, Larson DE, Anderson EA. Reduced sympathetic nervous activity. A potential mechanism predisposing to body weight gain. J Clin Investig 1993;92: $1730-5$.

18. Troisi RJ, Weiss ST, Parker DR, Sparrow D, Young JB, Landsberg L. Relation of obesity and diet to sympathetic nervous system activity. Hypertension 1991;17:669-77.

19. Bigger JT, Fleiss JL, Rolnitzky LM, Steinman RC. The ability of several short-term measures of RR variability to predict mortality after myocardial infarction. Circulation 1993;88:927-34.

20. Hrushesky WJ, Fader D, Schmitt O, Gilbertsen V. The respiratory sinus arrhythmia: a measure of cardiac age. Science 1984;224:1001-4.

21. Huikuri HV, Makikallio TH, Peng CK, Goldberger AL, Hintze U, Moller M. Fractal correlation properties of R-R interval dynamics and mortality in patients with depressed left ventricular function after an acute myocardial infarction. Circulation 2000; 101:47-53.

22. Kleiger RE, Miller JP, Bigger JT Jr, Moss AJ. Decreased heart rate variability and its association with increased mortality after acute myocardial infarction. Am J Cardiol 1987;59:256-62.

23. Makikallio TH, Hoiber S, Kober L, et al. Fractal analysis of heart rate dynamics as a predictor of mortality in patients with depressed left ventricular function after acute myocardial infarction. TRACE Investigators. TRAndolapril Cardiac Evaluation. Am J Cardiol 1999;83:836-9.

24. Bonora E, Targher G, Zenere MB, et al. Obesity worsens cardiovascular risk profiles independently of hyperinsulinaemia. J Intern Med 1997;241:463-70.

25. Vega GL. Results of Expert Meetings: Obesity and Cardiovascular Disease. Obesity, the metabolic syndrome, and cardiovascular disease. Am Heart J 2001; 142:1108-16.

26. Willett WC, Manson JE, Stampfer MJ, et al. Weight, weight change, and coronary heart disease in women. Risk within the 'normal' weight range. JAMA 1995;273:461-5. 
27. Heart rate variability: standards of measurement, physiological interpretation and clinical use. Task Force of the European Society of Cardiology and the North American Society of Pacing and Electrophysiology. Circulation 1996;93:1043-65.

28. Novak V, Saul JP, Eckberg DL. Task Force report on heart rate variability. Circulation 1997;96: 1056-7.

29. Akselrod S, Gordon D, Ubel FA, Shannon DC, Berger AC, Cohen RJ. Power spectrum analysis of heart rate fluctuation: a quantitative probe of beatto-beat cardiovascular control. Science 1981; 213:220-2.

30. Malliani A, Pagani M, Lombardi F, Cerutti S. Cardiovascular neural regulation explored in the frequency domain. Circulation 1991;84:482-92.

31. Pomeranz B, Macaulay RJ, Caudill MA, et al. Assessment of autonomic function in humans by heart rate spectral analysis. Am J Physiol 1985;248: H151-3.

32. Kamath MV, Fallen EL. Power spectral analysis of heart rate variability: a noninvasive signature of cardiac autonomic function. Crit Rev Biomed Eng 1993;21:245-311.

33. Montano N, Ruscone TG, Porta A, Lombardi F, Pagani M, Malliani A. Power spectrum analysis of heart rate variability to assess the changes in sympathovagal balance during graded orthostatic tilt. Circulation 1994;90:1826-31.

34. Rimoldi O, Pierini S, Ferrari A, Cerutti S, Pagani M, Malliani A. Analysis of short-term oscillations of $\mathrm{R}-\mathrm{R}$ and arterial pressure in conscious dogs. Am J Physiol 1990;258:H967-76.

35. Young JB, Macdonald IA. Sympathoadrenal activity in human obesity: heterogeneity of findings since 1980. Int J Obes Relat Metab Disord 1992;16: 959-67. 